\section{A new term in the global carbon balance}

SIR-The yearly carbon balance is unbalanced: man-made emissions of carbon dioxide into atmosphere, through combustion of fossil fuels and deforestation, are not fully accounted for by ocean adsorption and measured increase of $\mathrm{CO}_{2}$ in the atmosphere. Man can operate powerful disturbances on ecosystems; we will show he can also operate powerful segregation of carbon through a multiplicity of actions which altogether we propose to call "stock and waste" segregation.

Confining ourselves to the most recent estimates of anthropogenic emissions of carbon into the atmosphere, we have a flow of 5.2 gigatons $\left(10^{15} \mathrm{~g}\right)$ carbon per year coming from fossil fuel combustion ${ }^{1}$ and a flow from deforestation estimated either to be $0.9-2.5 \times 10^{15} \mathrm{~g} \mathrm{C} \mathrm{yr}^{-1}$ (ref.2) or $1.6 \pm 0.8 \times 10^{15} \mathrm{~g} \mathrm{Cyr}^{-1}$ (ref.3). The classical sinks for this total $\mathrm{C}$ flow, ocean adsorption (maximum rate $2.5 \times 10^{15} \mathrm{~g} \mathrm{C} \mathrm{yr}^{-1}$ ) and increase of $\mathrm{CO}_{2}$ in the atmosphere (measured rate of $2.3 \times 10^{15} \mathrm{~g} \mathrm{C} \mathrm{yr}^{-1}$ ) are evidently not large enough to accommodate for emissions. We therefore need one or more new carbon sinks.

While revision of older mechanisms is going on and new mechanisms await better understanding and quantification ${ }^{3}$, we wish to draw attention to a new carbon segregation path whose existence seems to us beyond any doubt.

The fundamental starting point is to recognize that each of the 4,000 million people in the world, within their social and economic structure, is entitled to the possession or use of an array of commodites and services, each having a material base and therefore a carbon content. The ensemble of these posessions, which in developed countries covers an impressive variety of objects, is what we call stock.

In societies recording a continued increase in the standard of living after correction for population growth, stock increases every year.

The carbon content of the global annual increase of stock is a sink that needs evaluation. But commodities and services do not last for ever. Goods must be renewed and new products displace older ones. This creates an enormous flow of materials - the flow of waste.

Whenever waste is not somehow "recycled" but, as in landfilling or dumping, essentially subtracted from natural cycles, its carbon content is segregated for many years. This represents the waste component of our stock and waste segregation mechanism.

Our group is still working on the quantitative evaluation of the stock and waste mechanism in terms of the amounts of carbon that are segregated every year. We can, however, give some preliminary results which show that stock and waste must be taken into account as a term in a correct carbon balance of the world.

As an example of stock increase, we took into consideration the Food and Agricultural Organization ${ }^{4}$ data on wood production in 1982, during which the wood and pulp and paper industries dealt with $0.7 \times 10^{15} \mathrm{~g}$ of carbon. Looking at final uses of this carbon ${ }^{5}$, at least $0.45 \times 10^{15} \mathrm{~g} \mathrm{C}$ $\mathrm{yr}^{-1}$ are accumulating in the stock, whereas the rest enters the flow of waste.

Considering the waste contribution to the carbon sink, we note that despite the fact that we are the only producers, our knowledge of global waste production is very uncertain.

Recent data on 10 European countries with a population of 270 million people show that total waste reaches a value of 2 gigatons per year (W. Ganapini, personal communication); a very conservative extrapolation gives a value of at least 7 gigatons for the world.

Heating values for wastes are in the range $800-3,000 \mathrm{kcal} \mathrm{kg}^{-1}$ (ref. 6); an average value of $1,200 \mathrm{kcal} \mathrm{kg}^{-1}$ gives, according to the correlation shown by Til$\operatorname{lman}^{5}$, a content of $10 \%$ of carbon; assuming that $50 \%$ of this waste is subtracted from any substantial oxidation, waste is responsible for the segregation of an impressive amount of carbon, at least $0.35 \times 10^{15} \mathrm{~g} \mathrm{C} \mathrm{yr}^{-1}$.

Thus the evaluation of just a few terms of the stock and waste mechanism already shows its importance: anthropogenic contribution to carbon subtraction ranks of some $10^{15} \mathrm{~g}$ every year. Carbon balance must be accordingly modified.

UMBERTO BIANCHI LUigi Musi Marina PicARdi Eugenio Piovano

Institute of Industrial Chemistry,

University of Genoa,

C.so Europa 30 ,

16132 Genoa, Italy

. Woodwell, G.M. et al. Science 222, 1081 (1983).

Houghton, R.A. et al. Nature 316, 617 (1985)

Bolin, B. The Greenhouse Effect, Climatic Change and Ecosystems (Wiley, Chichester, in the press).

4. Production Yearbook, FAO (Rome) 1982.

5. Tillman. D A. Wood as an Energy Resource (Academic. London, 1978)

6. Cassitto, L. \& Magnani, P. Ambiente e Sicurezze, 44 (November 1983)

\section{$X$ chromosomes and dosage compensation}

SIR-The contention of Chandra ${ }^{1.2}$ that the primary function of $\mathrm{X}$-chromosome inactivation is one of sex determination rather than dosage compensation is difficult to justify for more reasons than those considered by Lyon ${ }^{3}$. When examined in the context of the homomorphic sex chromosomes of diploid dioecy and in relation to the $\mathrm{X}$ and $\mathrm{Y}$ of haploid dioecy, the thesis is untenable.

Sex determination which depended solely on differential inactivation in one or other of a pair of homologues must be recognized as environmental or phenotypic. There is therefore no reason to suppose that alleles related to secondary sexspecific characters would accumulate preferentially in either homologue, for each chromosome could play the role of an $\mathrm{X}$ or $\mathrm{Y}$ in different individuals. Genetic fixation of sex determination is thus an essential precursor to the evolution of heteromorphic sex chromosomes in an $\mathrm{XX} / \mathrm{XY}$ or $\mathrm{ZZ/ZW}$ system, and the same is true of the haploid X/Y system of bryophytes ${ }^{4.5}$.

In many mosses and liverworts there are reports of homomorphic sex chromosomes where the $\mathrm{Y}$ of male plants differs from the $X$ of females only in the greater extent of its heterochromatin which, there is evidence to suggest ${ }^{6}$, is facultative. It has been seen in terms of more extensive gene inactivation of secondary female characters in the $\mathrm{Y}$ than of male characters borne by the $\mathrm{X}$, characters which it is hypothesized are thus located as a consequence of an earlier monoecious condition ${ }^{4.5}$. If sex-determining factors were not chromosomally fixed, both of these homologues would be variously phenotypic X or Y chromosomes. Evolution of heteromorphic $\mathrm{X}$ and $\mathrm{Y}$ chromosomes, as seen in many families and genera, would not then have followed. Instead, limited but equal erosion of the $\mathrm{X}$ and $\mathrm{Y}$ would be an expected consequence if crossing-over were excluded from lengths of chromosomes bearing secondary sexual characters $^{7}$, whereas no significant erosion would occur in the absence of chiasma localization.

Department of Botany,

M.E. NewToN

University of Manchester,

Manchester M13 9PL, UK

1. Chandra, H.S. Proc. natn. Acad. Sci. U.S.A. 82, 6947-6949 (1985).

2. Chandra, H.S. Nature 319, 18 (1986).

3. Lyon, M.F. Nature 320, 313 (1986)

4. Newton, M.E. in The Experimental Biology of Bryophytes (eds Dyer. A.F. \& Duckett, J.G.) 65-96 (Academic, London, 1984).

Newton, ME Bull, Br. bryol. Soc, 45, 9 (1985)

6. Newton. M.E. in New Manual of Bryology Vol. I (ed Schuster, R.M.) 117-148 (Hattori Botanical Laboratory, Nichinan-shi, 1983).

7. Bull, J.J. A. Nat. 112,245-250 (1978)

\section{Motions of the images of atoms}

SIR-Howie might have missed an alternative explanation for motions of atom images under the electron microscope in his article "Coulomb explosions in metals" (Nature 320, 684; 1986). The observations made by the groups whose work he reports consist of apparent movement of atoms or columns in gold microcrystals when imaged in the electron 